\title{
How Much Is Enough? The Politics of Technology and Weaponless Nuclear Deterrence
}

\author{
Anne Harrington and Matthias Englert
}

\begin{abstract}
This chapter contributes to the literature on nuclear proliferation by bringing theoretical resources from political philosophy and science and technology studies (STS) to bear on perennial questions for scholars of international relations (IR): "Why do states build nuclear weapons?" and "How many nuclear weapons are enough to sustain a credible nuclear deterrent?" We argue that states build nuclear weapons when they perceive the benefits of creating and maintaining a nuclear arsenal as outweighing the costs. If, therefore, a state is able to reap the benefits of having a nuclear weapon without actually creating one, it will have no reason to forego membership in the Nonproliferation Treaty. Furthermore, states with latent nuclear weapon programs are already actively engaging in a form of "weaponless" nuclear deterrence. Far from existing only in imagination, the "virtual" arsenals of the future are already observable in the nuclear security strategies of non-nuclear weapon states today. In making this argument, we draw on emergent theories of nuclear technopolitics that focus on the ambivalence of nuclear technology in constituting the political field of interactions.
\end{abstract}

Keywords Nonproliferation - Deterrence - International relations • Uranium enrichment $\bullet$ Centrifuge $\bullet$ Technopolitics

This chapter contributes to the literature on nuclear proliferation by bringing theoretical resources from political philosophy and science and technology studies (STS) to bear on a perennial question for scholars of international relations (IR): "What are the determinants of proliferation?" or as Scott Sagan so eloquently put it,

\author{
A. Harrington $(\bowtie)$ \\ American Political Science Association, Washington DC, USA \\ e-mail: aih@uchicago.edu \\ M. Englert \\ Ianus Institute, Technical University Darmstadt, Darmstadt, Germany \\ e-mail: matthias.englert@dialectics.de
}


"Why do states build nuclear weapons?" (Sagan 1996). IR scholars believe that if they can discover what causes states to build nuclear weapons, they can make better recommendations about how to enhance nonproliferation policy. Their goal is to predict, or "forecast", nuclear proliferation behavior. To that end, the IR literature provides three competing answers to the question of why states build the Bomb: security, domestic politics, and prestige. Each of these motives is believed to account for at least one case of proliferation, but there is no overriding consensus that any one of them alone is sufficient to explain the variation across cases.

In contrast, the argument we develop in this paper proceeds from a different set of assumptions. Our premise is that there is no "causal logic" driving proliferation behavior. Furthermore, debating the relative contribution of one motive versus another will not ultimately improve nonproliferation policy beyond what is known today. In fact, the framing of the debate in terms of "proliferation"-as if nuclear weapons were self-reproducing-biases the field towards a search for the next bomb, anticipating it by watching for signs that indicate its imminent arrival, rather than engaging in a political analysis of what is both possible and desirable for policymakers.

Instead of searching for a concealed motive- "the hidden bomb" so to speakin this paper we search on the surface for what is hidden in plain sight, namely that states build nuclear weapons when they perceive the benefits of creating and maintaining a nuclear arsenal as outweighing the costs. If, therefore, a state is able to reap the benefits of having a nuclear weapon without actually creating one, it will have no reason to proliferate. Contrary to the logic of proliferation, we start from the assumption that possessing nuclear weapons makes some states less, rather than more secure.

The appropriate question to answer from this point of view is not "What are the determinants of proliferation?" but rather, "How much is enough?" by which we mean, at what point does a state's nuclear program become a burden rather than a benefit? For some states, even a modest nuclear energy program is simply unobtainable without significant aid because they lack access to the necessary materials and expertise. For others, the answer is more ambiguous. So-called latent-nuclear states possess the scientific expertise and technology to build both robust nuclear energy and nuclear weapon programs, but prefer to stop developing those capabilities short of creating a nuclear warhead.

Our contention in this paper is that states with latent nuclear weapon programs are already actively engaging in a form of "weaponless" nuclear deterrence. Far from existing only in imagination, our contention is that the "virtual" arsenals of the future are already observable in the nuclear security strategies of non-nuclear weapon states today.

In making this argument, we draw on emergent theories of nuclear technopolitics that focus on the role of nuclear technology in constituting a field of political interactions. In contrast to Cold War-era technostrategic theories of nuclear deterrence and proliferation, we build a technopolitical explanation of nuclear politics. Technostrategic theories assign agency to technology. They reduce humans to rational actors whose job it is to discern and implement optimal strategies 
in response to technological incentives. Instead of positing a determinate role for technology, we contend that technology impacts human agency by altering the range of possible action. Technology does not dictate a correct strategy or answer, but it does constitute a range of available options.

In the case of nuclear weapons, the scientific discovery of nuclear fission brought into existence the technopolitical field of nuclear politics. However, nuclear technology does not determine actions within that field in a mono-causal way. Far from being determinate, nuclear technology is inherently ambivalent. It does not have a singular, politically neutral meaning. Rather, the fact that different groups can simultaneously read different meanings into the technology is its defining feature (Abraham 2010; Liebert et al. 1994). Thus, a country can be in compliance with its commitment as a non-nuclear weapon state under the Treaty on the Nonproliferation of Nuclear Weapons (NPT) and simultaneously be maintaining a weaponless nuclear deterrent.

This chapter has five sections, including the conclusion. We start out by introducing the nuclear nonproliferation regime, the primary feature of which is the boundary it creates between the managed systems of deterrence and abstinence. This is the battleground of nuclear technopolitics. Power struggles over where a state is entitled to locate itself vis-à-vis this boundary are the primary source of conflict. In the second section we describe the two technological pathways to the bomb, focusing in particular on the ultracentrifuges for uranium enrichment. Centrifuges are controversial because they convert natural uranium, which is widely available, into material appropriate to power a nuclear reactor or produce a nuclear weapon. The NPT does not specify what specific technologies a state is entitled to possess short of a nuclear explosive device, only that the technology must be intended for peaceful purposes. Therefore the only restriction on centrifuge enrichment is the difficulty of mastering the technology. Technical knowledge of these two pathways is the substance of subsidiary nonproliferation agreements detailing inspection and verification requirements. Familiarity with what is and is not technically possible is foundational knowledge necessary to understanding nuclear politics. In the third section we bring together the international political structure with the technology it is designed to regulate to show how the ambivalence of nuclear technology shapes political possibilities within the technopolitical field of nuclear politics. In the fourth section, we extend that same argument to the practice of weaponless nuclear deterrence. Finally, we draw out the political implications of our argument with respect to the contemporary conflict over Iran's nuclear program.

\section{Nuclear Technopolitics and the Nonproliferation Regime}

The field of nuclear politics is a system of governance in which a state's status and access to resources is linked to its ability to manipulate the ambivalence of nuclear technology in a battle for political ends. The most important aspect of understanding this field is unpacking how the nature of nuclear technology — what is known to 
be possible in the realm of scientific and technical knowledge about the ability to produce, detect, and manipulate matter - interacts with and conditions the political.

Unlike other international treaty regimes, in the realm of nuclear politics relationships between states are mediated through technology The ambivalence of nuclear technology allows for the immediate political purpose of nonproliferation agreements to remain ambiguous within the carefully choreographed boundaries of official diplomatic circles. Scientists always play an essential role in deciding what political leaders will (and will not) cover at international nuclear negotiations because the substance of these negotiations is technological in nature. Therefore, the boundaries of the negotiations, and the terms of the final agreement, take the form of permissive and restrictive technical barriers.

Even if uniformly applied, technical barriers impact states differentially given the technologies and materials available to each state. Most significantly, the NPT divides the world into two categories of states based on what technology they possessed as of January 1, 1967: nuclear weapon states and non-nuclear weapon states. In order to qualify as a nuclear weapon state, a country must have tested a nuclear explosive device prior to that date. Though this rule is applied equally to all states, it is de facto discriminatory because it impacts states differentially by fixing their status under the treaty to their technological achievements at a single point in time. Only five states are recognized nuclear weapon states (US, Russia, China, UK, France).

Rather than addressing the just or unjust nature of its particular political order, the nonproliferation regime bases its legitimacy on the common interest among states in combating the unique threat that nuclear war poses to the world. As Hans Morgenthau explained, nuclear war is no longer a first-order death in which individuals sacrifice their existence for the perpetuation of society, but rather a 'second death' that threatens to destroy meaning itself (Morgenthau 1961). Nuclear war is a cataclysmic event because it will not only end life within the war zone, but scientists predict that the fallout will black out the sun, lower the temperature of the earth and usher in a 'nuclear winter.' Previously, effects and unintended consequences of specific technologies were confined by geography and time. Today humanity holds survival in its own hands and has become responsible for its future.

As a counterbalance to this discriminatory framework, all states party to the treaty are obligated to work towards a world in which all states will become equal through nuclear disarmament. The legitimacy of the NPT is sustained by constantly reaffirming the primacy of the threat posed - not by nuclear weapon states, but by the technology itself-through a constant re-iteration of the desire for complete disarmament as the unifying mission that binds together all members (Harrington de Santana 2011).

Article VI of the Nonproliferation Treaty expresses this Cold War-era consensus about the desirability of disarmament but it was a consensus that postponed disarmament indefinitely. As codified, Article VI is not an agreement to disarm, but rather a meta-level commitment "to pursue negotiations in good faith." In other words, the commitment is to the pursuit itself, not actual disarmament. 
Since the end of the Cold War and the indefinite extension of the NPT the commitment of the nuclear weapons states to the pursuit of nuclear disarmament, and the US commitment in particular, have come into question (Daase 2003). This has lead to multiple reaffirmations of the importance of this goal to the legitimacy of the NPT. The importance of this commitment to the pursuit of disarmament was reaffirmed at the 2010 NPT Review Conference in the final document, which emphasizes "that the strict observance of all the provisions of the Treaty remains central to achieving the shared objectives of the total elimination of nuclear weapons" (NPT 2010). US President Barack Obama has also reiterated the US commitment to nuclear disarmament. The Obama administration's 2010 Nuclear Posture Review spells out the perception that the existence of a common goal motivates compliance with the NPT, saying that "[b]y demonstrating that we take seriously our NPT obligation to pursue nuclear disarmament, we strengthen our ability to mobilize broad international support for the measures needed to reinforce the non-proliferation regime and secure nuclear materials worldwide" (United States Department of Defense 2010). Even for policymakers in the United States who do not perceive the vision of a nuclear-weapon-free world to be realistic in the short term, such as the Cold War-era American statesmen, Sam Nunn, George Shultz, William Perry and Henry Kissinger, the commitment to the vision is still essential because it ensures that the steps that the United States is advocating to limit access to nuclear materials will be "perceived as fair and urgent" (Nuclear Security Project 2010).

\subsection{The Managed Systems of Deterrence and Abstinence}

For the foreseeable future, the NPT divides the realm of nuclear politics into two interrelated technopolitical economies: An economy of deterrence, and an economy of nonproliferation, or what William Walker refers to as the managed systems of deterrence and abstinence (Walker 2000).

\subsubsection{The Managed System of Deterrence}

According to Walker, the managed system of deterrence consists, among other things of "a set of understandings and practices, expressed in the 'deterrence theories' of Brodie, Schelling and others and enunciated in nuclear doctrine, of how military forces of various kinds should be deployed and managed to provide mutual vulnerability and restraint." Bernard Brodie was one of the primary authors of this system. In his contribution to the 1945 edited volume, The Absolute Weapon, Brodie formulated the two foundational principles of Cold War-era nuclear deterrence. The first principle is to ensure the capacity for retaliation in kind, the ability to absorb a nuclear attack and strike back. The second principle is that nuclear weapons, unlike other types of weapons, should be produced for the primary 
purpose of preventing their consumption through detonation in acts of war (Brodie 1945).

Back when Bernard Brodie first introduced the idea that the American military establishment should be reorganized for the purpose of preventing war his suggestion was considered crazy at best and dangerous at worst (Kaplan 1991). Today it is taken for granted within certain expert communities that deterrence "works." Deterrence is a doctrinal term. The American military under the Obama administration defines it as "The prevention of action by the existence of a credible threat of unacceptable counteraction and/or belief that the cost of action outweighs the perceived benefits" (United States Department of Defense 2014). Yet, in the 1950 s, nuclear deterrence was (and still is for some) a controversial idea because it fundamentally altered the field of international politics. The existence of nuclear weapons foreclosed the possibility of total war as a mechanism for dispute resolution. Unlike the optimistic assessments of easy victory that inevitably precede the slow decent into a war of attrition, the pyrrhic victory of a nuclear war is easily foretold. Even for those who defend the concept of victory in a nuclear war, they cannot deny that both sides inevitably stand to lose more than they will gain. Therefore, countries that master the art and science of nuclear deterrence enter a new realm in which force is no longer the ultima ratio of international politics, yet at the same time there is no escape from the constant threat of nuclear war.

\subsubsection{The Managed System of Abstinence}

The managed system of abstinence is a function of the basic bargain of the NPT between nuclear weapon states and non-nuclear weapon states. Non-nuclear weapon states agree to abstain from developing nuclear weapons in return for access to nuclear energy technology and the promise that nuclear weapon states will work towards disarmament. The NPT forbids nuclear weapon states (NWS) to "assist" non-nuclear weapon states (NNWS) and NNWS to "manufacture" or "seek or receive any assistance" to "manufacture or otherwise acquire a nuclear weapon, or other nuclear explosive devices" (NPT 1968).

The NPT defines the boundary between these two systems as the manufacture of a "nuclear explosive device" because the ability to produce nuclear weapons was considered a necessary first step in creating a nuclear deterrent. Yet, even non-nuclear weapon states under Article V of the treaty are entitled to "potential benefits from any peaceful applications of nuclear explosions" and "the charge to such Parties for the explosive devices used will be as low as possible and exclude any charge for research and development" (NPT 1968).

Today the idea of a peaceful nuclear explosive device is considered risible, but the interpretation of all nuclear explosions as "weaponization" evolved slowly over time. In the 1960s when the NPT was under negotiation it was still believed that nuclear explosive devices might be used for purposes such as excavation, and ensuring access to these applications of the explosive potential was considered consistent with the Article IV guarantee that "Nothing in this Treaty shall be 
interpreted as affecting the inalienable right of all the Parties to the Treaty to develop research, production and use of nuclear energy for peaceful purposes" (NPT 1968).

\subsubsection{The Battleground of Nuclear Technopolitics}

Defending the boundary between the realm of deterrence and the realm of abstinence is the primary battleground of nuclear politics. What technologies non-nuclear weapons states are and are not permitted as part of the "inalienable right...to develop research, production and use of nuclear energy for peaceful purposes" is the space in which the struggle for political interpretation of nuclear technology plays out as countries joust over whether a certain technology will be coded as civilian or military for the purposes of political action. However, as we explain below, it is not possible to distinguish between a civilian and a military program simply on the basis of what technology a country possesses-although certain items and processes are more suspect than others. Establishing intent by answering the question of whether or not a program is civilian or military is an inherently political act, and the spread of the most sensitive elements of the fuel cycle is therefore considered by some to constitute a threat to the stability of the Nonproliferation Regime. For instance, Kofi Annan, then-Secretary-General of the United Nations, argued at the 2005 NPT Review Conference that sensitive technologies will destabilize the nonproliferation regime by undermining the function of the inspections carried out by the International Atomic Energy Agency (IAEA) (Zarate 2007 citing Annan 2005). The IAEA is the organization that verifies compliance with the NPT by upholding a regime of safeguards that comprise a series of technical measures to ensure that no fissile material known to the IAEA is diverted for military purposes. The measures range from cameras at certain positions, to the visit of inspectors to take probes and samples, count and weigh materials, tag and seal containers or conduct other visual inspections.

The allowed locations and methods of such inspections are limited under comprehensive safeguards agreements. Almost all countries party to the NPT have signed a safeguards agreement. Under these agreements the IAEA is charged with detecting in a timely manner the diversion of declared fissile materials. If a state has signed the next level of agreement, known as an additional protocol, it grants the IAEA complementary inspection authority to also detect possible undeclared activities (IAEA 2014).

All of these measures are designed to provide timely warning of noncompliance. However, as Albert Wohlstetter famously warned:

If, in fact, technological transfers can bring a "nonnuclear weapons state" within weeks, days or even hours of the ability to use a nuclear explosive, [then] in the operational sense that "nonnuclear weapon state" will have nuclear weapons. The point is even more fundamental than the fact that effective safeguards [according to the IAEA] mean timely warning. A necessary condition for timely warning is that there be a substantial elapsed 
time. But if there is no substantial elapsed time before a government may use nuclear weapons, [then] in effect it has them (Zarate 2007 citing Wohlstetter et al. 1979).

This same line of reasoning is what led Mohammed el-Baradei, former IAEA director, to the conclusion that once non-nuclear weapon states master the nuclear fuel cycle, they become "virtual nuclear weapon states" (Baradei 2005). Virtual nuclear weapon states have mastered at least one of the technological processes for the production of fissile materials, a necessary step in the production of nuclear energy or nuclear weapons. They can produce Uranium 235, Plutonium 239, or both.

\section{Pathways to the Bomb: The Technical Dimension of Nuclear Technopolitics}

There are two technological pathways to the bomb: uranium enrichment and plutonium production. In this article we focus on enrichment. The argument about technological potentials and their effects on deterrence applies also to the plutonium path to the bomb. All nuclear reactors using uranium fuel produce plutonium as a bi-product of energy production and are therefore a proliferation concern. However, nuclear reactors large enough to be a proliferation concern are difficult to conceal. Additionally, extracting plutonium from highly radioactive fuel requires shutting down the reactor and accessing the nuclear fuel in the reactor core. Other than changing out the spent fuel and refueling the reactor, there is no reason to access the core. Therefore, timely warning is considered less of a concern with reactors than it is with uranium enrichment facilities.

Although natural uranium is plentiful in nature, to be weaponized it must be converted into a form that can be used to sustain a nuclear chain reaction. Natural uranium is made up almost entirely of two isotopes, one of which is the slightest bit heavier than the other. Only the lighter isotope, U-235, is useful for sustaining a chain reaction. Fortunately, at least from a nonproliferation perspective, natural uranium is $99.3 \% \mathrm{U}-238$, so in order to be weapons usable it must be "enriched" to increase the percentage of desirable U-235 up to roughly $90 \%$ (highly enriched uranium-HEU) by separating out the undesirable U-238. ${ }^{1}$ Uranium enrichment facilities are still difficult to build, but a facility sufficient to produce several bombs worth of highly enriched uranium is relatively easy to hide.

Enrichment can be done by different physical or chemical methods. Today centrifuge enrichment is the most efficient and economical technology for uranium enrichment. In a centrifuge the lighter U-235 is separated from the heavier U-238. The natural uranium is first converted into the chemical molecule uraniumhexafluoride (UF6), in a separate conversion facility. Uraniumhexafluoride becomes

\footnotetext{
${ }^{1}$ Instead of enriching the U-235 content, the U-238 can also be converted into plutonium, a completely different element, by irradiating U-238 with neutrons in a nuclear reactor.
} 
solid at atmospheric pressures and temperatures below $56.5^{\circ} \mathrm{C}\left(133.8^{\circ} \mathrm{F}\right)$. The solid UF6 is then transported in heavy storage cylinders, each weighing several tons, to a centrifuge facility, where the solid is converted to gas form and fed into underpressured pipes of a centrifuge facility. The gas is then pumped into the centrifuge - a stovepipe-like cylinder typically $10-20 \mathrm{~cm}$ in diameter and up to several meters long. Among the fastest spinning things on earth, centrifuges rotate more than 1,000 times per second. Their extreme centrifugal force presses the slightly heavier U-238 a little bit further toward the outside wall of the rotor than the lighter U-235. As a result, a very thin film of gas, now enriched with a marginal amount of additional U-235, forms on the wall. This enriched-gas film can be extracted and siphoned into another centrifuge for further enrichment. This process is repeated until the desired level (\%) of enrichment is achieved.

The process of enrichment can be stopped at any point in the process making it possible to distinguish between different levels of enrichment for different purposes. The limit of $20 \%$ enrichment is the accepted international norm that distinguishes military from civil use. Low-enriched uranium for civilian uses contains less than $20 \%$ U-235, but once a state reaches that threshold, it has completed roughly two thirds of the work necessary to reach the minimum level for weapons-grade material: $90 \% \mathrm{U}-235 .^{2}$

The percentage change achieved with only one centrifuge is quite low. To reach higher enrichment levels 10-20 stages (groups of centrifuges connected in parallel) have to be used in series, depending on the enrichment level of the final product. Additionally the gas stream entering and exiting a centrifuge is limited and many centrifuges have to be used in parallel in each stage. To maximize the efficiency, the enriched stream and the waste stream are both reused to squeeze out the maximum amount of U-235 and minimize the total gas flow forcing the serial and parallel arrangement of centrifuges into what is known as a cascade. Centrifuges are installed in rows in a cascade hall. The gas stream passes through steel pipes that connect one centrifuge to another. The shape of the cascade is created by the pattern of the pipes. A typical cascade of very simple first generation centrifuges would contain 164 centrifuges.

Centrifuges are a technological feat. The stress on the material due to the speed of the rotor wall challenges the metallurgical and fabricating skills of the manufacturer. High precision manufacturing is not only needed for the rotor, but also for the bearings and other rotating components. Any irregularities in the rotor will cause imbalances. Even a fingerprint on the rotor of a centrifuge would cause it to spin out of control and the centrifuge would mechanically explode.

\footnotetext{
${ }^{2}$ This can be visualized starting with a natural uranium mix ( $0.7 \%$ enrichment) of 140 uranium238 atoms (black balls) and 1 uranium-235 atom (red ball) in a salad bow. To enrich, black balls have to be sorted out. Taking out 70 black balls enriches to $1.4 \%$, taking out another 46 black balls enriches to $\sim 4 \%$ which is roughly the enrichment used in commercial light water reactors. The mix contains 24 black balls and 1 red ball. We took out 116 black balls from a total of 141 balls, which is more than $2 / 3$ of the work.
} 
With manufacturing equipment diffusing all over the world and with the help of a sophisticated supply network, the ability to manufacture centrifuges has come within the grasp of many countries. In addition to the five NPT-recognized nuclear weapon states, there are nine more countries with enrichment technology: Argentina, Brazil, Germany, India, Iran, Japan, the Netherlands, North Korea and Pakistan (International Panel on Fissile Materials 2013). Iran, for instance, bought centrifuge technology from Pakistan, which delivered the P1 design based on an early design stolen from the company URENCO in the 1970s. This design was known to be delicate to handle. Since the public disclosure of Iran's clandestine centrifuge program, Iran had to rely on reverse engineering, as it could no longer rely on advice from Pakistani experts. In hindsight, it might have been a better choice for Iran to develop an indigenous design right from scratch. However, beyond the centrifuge, an enrichment plant also requires a whole bundle of specialized equipment like pumps and high nickel alloy steel pipes to withstand the extremely corrosive UF6 environment in an enrichment facility. Iran partly bought this equipment from the international market but also manufactured it themselves and over the years became increasingly adept at handling the technology on its own.

\subsection{Options for Military Use}

To use a centrifuge facility for military purposes a country has three options (Hecker et al. 2012): It can use its declared facilities covertly; use a clandestine facility; or break-out and leave the NPT and use its facilities as it likes.

In order to covertly use a declared facility designed for low enrichment to enrich uranium to weapons-grade, a proliferator would either have to cycle UF6 through the same unaltered cascade several times to stepwise increase the enrichment (batch-recycling) or change the cascade shape and reconnect the gas tubes of the centrifuges to have more stages in series for a higher final enrichment. In a declared facility the only question is, when such a military use would be discovered. Another method of diversion is to use a declared facility to produce a stock of pre-enriched LEU that can be diverted to a secret small clandestine facility. As we showed above, most of the separative work is already done enriching to $20 \%$. A state could use the ambivalence of the technology to advance its latent capabilities for later use or just in case. (Arguably this is what Iran has done.)

Alternatively, clandestine facilities could be used secretly in parallel to a civil program or they could be fed by pre-enriched uranium stocks diverted from a civil program. It is almost impossible to remotely detect a clandestine uranium enrichment facility that uses centrifuge technology because their visible, thermal and radioisotopic signatures are very low. They are the same size as a larger supermarket, use no more electricity than a big box store, and do not emit many radioisotopes. As centrifuge facilities can be completely submerged underground, detection can only be based on intelligence information e.g. import of critical equipment or insider information etc. Plutonium, in contrast, must be generated by the neutron 
capture reaction of uranium-238. Therefore, producing plutonium requires an intense neutron source like a nuclear reactor to produce neutrons and irradiate uranium-238, the existence of which is much easier to detect, as it produces a lot of heat. Additionally the plutonium has to be separated from the uranium after irradiation, which releases detectable radioactive gases.

The third option is to withdraw from the NPT once a country decides to leave the NPT, it is legally entitled to do so as long it provides 3 months notice. At that point it could use its declared and possibly undeclared facilities as it wants to. However this option is likely to stir an international response by the UN Security Council and/or the General Assembly. The reaction of the international community would be very strong, up to and possibly including military action, so the incentive for doing so would have to be very high.

\section{The Right to Nuclear Technology for Peaceful Purposes and the Centrifuge as a Hybrid Object: The Political Dimension of Nuclear Technopolitics}

Non nuclear weapon states, including those without their own enrichment capabilities, often prefer to interpret their Article IV "inalienable right...to develop research, production and use of nuclear energy for peaceful purposes", to give them a per se right to sensitive technologies, including uranium enrichment facilities. Citing the Nonaligned Movement's (NAM) rationale, for instance, analyst Robert Zarate explains that, "Although Article IV never explicitly mentions enrichment, reprocessing and other nuclear fuel-making activities, some governments nevertheless interpret Article IV as implicitly recognizing the specific or per se right of signatories to any nuclear technological activities that can be conceivably labeled "peaceful" - short of actually inserting fissile material into a nuclear explosive device" (Zarate 2007). Of the 14 countries with uranium enrichment facilities as of 2013, 6 are NPT-recognized NNWS with enrichment capabilities: Argentina, Brazil, Germany, Iran, Japan, and the Netherlands (International Panel on Fissile Materials 2013).

However, technology for uranium enrichment is strictly controlled, and the inalienable right to its possession for peaceful purposes is hotly disputed (Ford 2005; Zarate 2007) because there are almost no technical hurdles to convert a declared centrifuge facility designed for civilian operation for military purposes. Zarate and others, including Christopher Ford, former US Special Representative for Nuclear Nonproliferation under President George W. Bush, contest the NAM's permissive interpretation of Article IV. As Special Representative, Ford argued that the development of sensitive technologies associated with the production of nuclear fuel goes beyond the minimum technology necessary to produce a peaceful program in compliance with the NPT. In essence, the NPT guarantees that NNWS will have access to nuclear fuel and therefore they should not produce it themselves. An 
independent nuclear fuel capability carries the implicit threat of an independent weapons program and therefore crosses the boundaries established between nuclear weapon states and non nuclear weapon states in Articles I, II, and III (Ford 2005).

Specifically, the ambivalence of centrifuge technology has two effects on the shape of the technopolitical field. First, it undermines the desire to draw a firm boundary between the managed system of deterrence and the managed system of abstinence-adjudicating a priori between "peaceful" and "military" programs enshrined in Article IV of the NPT. In other words, the technology itself enables in potentia two uses. The potential for a military use of nuclear energy technology does not have to be recalled immediately. Once a state has mastered all steps to produce centrifuges, build cascades, produce uraniumhexafluride and handle it, this state has the latent potential to use its assets for military purposes once it makes a decision to do so. Even though the use in actus can be monitored and verified as long as a state adheres to its obligations it is only possible to de poste factum distinguish military from civil use. Secondly, capabilities and potentials participate in the political sphere. Ambivalence means more than just "dual-use" or a technical option to be used at some point when a state decides to weaponize. The intrinsic potential that comes with the specifics of centrifuge technology opens a space of ambivalence and uncertainty that carries a certain agency that can be used politically. In Bruno Latour's words the centrifuge becomes a hybrid object. The centrifuge exceeds its material existence by entering the realm of politics. As we explain in the following section, this hybrid object can become a weaponless nuclear deterrent.

\section{Nuclear Ambivalence and Weaponless Deterrence}

The basic operational principles of Cold War-era of nuclear deterrence-the existence of a secure second strike-capability produced primarily for the purpose of preventing, not winning a war-are premised on the particular constellation of speed and destructive force that the combination of nuclear warheads loaded on intercontinental ballistic missiles embodies. When we think of nuclear deterrence, therefore, we usually think of the deterrent effect as stemming from the punishment that can be inflicted by the launch of a nuclear attack. It is the destruction of a nuclear explosion that generates "costs." However, achieving a deterrent effect does not actually require that a state impose those costs. It requires that a state maintain a securely-stored nuclear arsenal. In other words, as Albert Wohlstetter famously argued in his article "The Delicate Balance of Terror," if your nuclear arsenal is vulnerable, it will invite attack from an opponent who calculates that she can wipe out your capability by striking first. Therefore, a secure second-strike capability also requires an opponent to perceive that there are costs associated with overcoming the measures you have taken to protect your nuclear weapons. Fortifying your arsenal is a form of what Glenn Snyder identified as "deterrence by denial" in his 1959 classic, Deterrence by Denial and Punishment. 
The US doctrinal definition quoted above-“"The prevention of action by the existence of a credible threat of unacceptable counteraction and/or belief that the cost of action outweighs the perceived benefits"-captures these two different methods of operationalizing deterrence. The first, deterrence by punishment is the basic premise of mutual assured destruction: discouraging nuclear attack by creating a credible threat that aggression will be met with retaliation in kind. Likewise, deterrence by denial is also a strategy for discouraging military aggression, but rather than being based on a principle of reciprocity, denial is achieved through constructing superior defenses.

The defenses required for deterrence by denial do not necessarily have to be impenetrable, although it would be preferable if they were, just formidable enough that an enemy will assess the cost of mounting an attack as outweighing any possible benefit. Hardening underground missile silos, or evading detection by storing missiles on nuclear-powered submarines that can loiter at great depths are both examples of increasing the costs of attack by making the target more difficult to destroy. The more difficult a target is to destroy, the more likely a country is to take casualties and have to put its own assets at risk to interdict it. Constructing a nuclear missile defense shield, the ultimate form of deterrence by denial, has always been considered something of a pipedream. Even in the heyday of President Reagan's Star Wars missile defense shield, credible scientists argued that the goal remained out of reach. And although today perceptions of the effectiveness of missile defense are changing as systems become more robust, many technological problems remain. In traditional deterrence theory, deterrence by denial is a technical problem to be solved through demonstrated capabilities, but deterrence by denial, just like deterrence by punishment, is also a political battle for credibility.

This distinction between "deterrence by punishment" and "deterrence by denial" highlights the complex relationship between 'use-value' and 'threat-value' implicit in all definitions of deterrence (Harrington de Santana 2009). Punishment and denial are different kinds of use-value. They perform different operational functions because their material characteristics enable diverse sets of actions; use-value is defined by the universe of properties associated with the materiality of an object. It is an absolute form of value in the sense that it is measured relative to an accomplishment. So, for instance, a nuclear explosion can displace an impressive amount of earth or destroy a city. A solitary individual can realize the use-value of an object by benefiting from the actions and outcomes that technology enables regardless of anyone else's perceptions and behaviors. Threat-value, on the other hand, requires at least two actors and is what creates the deterrent effect. It is a relative form of value only indirectly related to the usefulness of the item. Threatvalue is realized not through the application of force to change the behavior of another, although the use of force can certainly increase the credibility of a threat of more to come, but rather in terms of the ability to manipulate the behavior of another in order to achieve an end not achievable through force alone.

In other words, threat-value is never reducible to use-value because the distinction is not only one of means, but also of the relationship between means and ends. The means-end relationship expressed by use-value is realizable in the present 
(Schelling 1966). The means-ends relationship expressed by threat-value is always about manipulating the behavior of another now, in the present, by invoking the image of a future in which the use of offensive or defensive weapons against them make them worse off than they are now. Deterrence is the practice of manipulating the relationship between use-value and threat-value in order to create the perception that the cost of military aggression will outweigh the benefits. It is never about now—only about what comes next.

The fact that threat-value is always realized only through the potential for future use opens up the possibility of pushing that potential for use always further into the future. Cold War-era theories of nuclear deterrence are all based on the presumption that in order for deterrence to be effective, the speed with which nuclear war could occur would mean that the potential for future use always had to be immediately at hand in the form of nuclear weapons on hair-trigger alert. However, in theory, that potential for future punishment could be pushed ever further into the future, as long as there is a stable expectation that an attack on the potential can be deterred through denial. This is the essence of "weaponless" nuclear deterrence. Weaponless nuclear deterrence can be practiced with either a latent nuclear capability such as the one embodied in a centrifuge, or a virtual capability, which is embodied in the simulation technologies possessed by advanced nuclear weapon states, or some combination thereof (Cohen and Pilat 1998; Mazarr 1995; Schell 1982).

Cold War-era strategic nuclear deterrence relied almost entirely on the threat of punishment rather than denial. In fact, one of the most counterintuitive features of the Cold War was that while arsenals needed to be invulnerable to attack, leaving cities vulnerable to attack was considered a virtue. Mutual vulnerability contributed to strategic stability by imposing a measure of self-restraint on both the US and the Soviet Union and provided an intellectual justification for their mutual agreement to forego anti-ballistic missile (ABM) technology in the ABM treaty (Schelling 1966; Bohlen 2003).

Weaponless deterrence, in contrast, reverses the technological requirements for the use-value on which the deterrent threat relies. Instead of foreswearing defenses, a state forswears its weapons. Having adequate defenses, especially for a country's nuclear facilities is essential, but all that is required in terms of a weapons capability is a credible commitment to the potential for reconstitution.

\section{Conclusion}

Recognizing the fact that the technopolitical features of nuclear deterrence are already operating carries implications both for how to best negotiate the circumstances of current conflicts and for the larger issue of whether or not deterrence is possible in a world without nuclear weapons. The intention of the NPT is to prohibit non-nuclear weapon states from having not only the explosive device itself, but the deterrent effect that the device enables. However, capturing that effect does not necessarily require the construction of a weapon or explosive device. An effective 
nuclear deterrent, in the form of a latent nuclear capability defined as unfettered access to fissile materials through a domestic production capacity, can contribute to a strategy of "weaponless" nuclear deterrence. As long as the costs of taking military action to destroy that capability are perceived as outweighing the benefits, it is possible for a state to both reap the benefits of membership in the NPT as a non-nuclear weapon state, and participate in the economy of nuclear deterrence by securing diplomatic talks with the recognized nuclear weapon states.

In conclusion, to take a current example, one implication of this argument is that Iran is already drawing on the inherent ambivalence of nuclear technology to cross the boundary from the managed system of abstinence into the managed system of deterrence. Iran was unable to establish a direct diplomatic relationship with the US, despite its attempts to do so, until it was able to engage the US in negotiations about its nuclear program. Analysts who debate the dichotomous nature of Iran's nuclear program, presupposing that it must be either "peaceful" or "military" are blind to the way that Iran is manipulating the inherent ambivalence of the technology in order to gain the benefits of having a nuclear weapon capability without bearing the costs of losing membership in the NPT - a change of status that would have long-term implications for its regional security as it would give other countries a reason to build nuclear weapons as well. They are also blind to the fact that the ambivalence of the nuclear technology may also be holding together a diverse political coalition within Iran, allowing each faction to project onto the program the potential they would like to see in it. While it is important for the IAEA to offer its assessment of whether or not Iran has crossed the line between a peaceful program for the purposes of political action, the job of analysts is not necessarily to offer a political determination that participates as a political football in the policy process by lending legitimacy to the assessment of Iran's intentions as "peaceful" or "military." It is also to provide perspective on that political debate by building an accurate picture of the phenomenon under question and in the process, open up new possibilities for future political action.

\section{References}

Abraham, I. (2010). 'Who's next?' Nuclear ambivalence and the contradictions of non-proliferation policy. Economic and Political Weekly, 45(43), 18-20.

Annan, K. (2005, May 2). Secretary-General's address to the nuclear non-proliferation treaty review conference. New York, NY. http://www.un.org/apps/sg/sgstats.asp?nid=1427. Accessed January 7, 2014.

Baradei, M. E. (2005, May 6). U.N.’s ElBaradei warns of nuclear apocalypse. Reuters.

Bohlen, A. (2003). The rise and fall of arms control. Survival, 45(3). http://faculty.maxwell.syr. edu/rdenever/PPA-730-27/Bohlen.pdf. Accessed January 6, 2014.

Brodie, B. (1945). The absolute weapon: Atomic power and world order. New York, NY: Harcourt, Brace and Company.

Cohen, A., \& Pilat, J. (1998). Assessing Virtual Nuclear Arsenals. Survival, 40(1), 129-144. 
Dasse, C. (2003). Der Anfang vom Ende des nuklearen Tabus: zur Legitimitätskrise der Weltnuklearordnung. Zeitschrift für Internationale Beziehungen, 10(1), 7-42.

Ford, C. A. (2005, May 18). NPT Article IV: Peaceful uses of nuclear energy. New Paradigms Forum. http://www.newparadigmsforum.com/NPFtestsite/?p=1518. Accessed January 6, 2014.

Harrington de Santana, A. (2009). Nuclear weapons as the currency of power: Deconstructing the fetishism of force. The Nonproliferation Review, 16(3), 325-345.

Harrington de Santana, A. (2011). The strategy of nonproliferation: Maintaining the credibility of an incredible pledge to disarm. Millennium-Journal of International Studies, 40(1), 3-19.

Hecker, S., Englert, M., \& Miller, M. (2012). Nuclear non-proliferation. In D. S. Ginley \& D. Cahen (Eds.), Materials in energy (pp. 162-177). Cambridge: Cambridge University Press.

IAEA. (2014). Factsheets and FAQs: IAEA safeguards overview: Comprehensive safeguards agreements and additional protocols. http://www.iaea.org/Publications/Factsheets/English/ sg_overview.html. Accessed January 6, 2014.

International Panel on Fissile Materials. (2013). Facilities: Uranium enrichment. Last edited July 2013. http://fissilematerials.org/facilities/uranium_enrichment.html. Accessed January 6, 2014.

Kaplan, F. (1991). The wizards of armageddon. Stanford: Stanford University Press.

Liebert, W., Rilling, R., \& Scheffran, J. (1994). Die Janusköpfigkeit von Forschung und Technik Zum Problem der zivil-militärischen Ambivalenz. Marburg: BdWi.

Mazarr, M. J. (1995). Virtual nuclear arsenals. Survival, 37(3), 7-25.

Morgenthau, H. J. (1961). Death in the nuclear age. Commentary, 32(3), 231-234.

Nuclear Security Project. (2010). About the project. http://www.nuclearsecurityproject.org/site/c. mjJXJbMMIoE/b.3534665/k.5828/About_the_Project_Index.htm. Accessed August 25, 2010.

Sagan, S. D. (1996). Why do states build nuclear weapons? Three models in search of a bomb. International Security, 21(3), 54-86.

Schell, J. (1982). The fate of the earth. Stanford: Stanford University Press.

Schelling, T. (1966). Arms and influence. New Haven, CT: Yale University Press.

Treaty on the Nonproliferation of Nuclear Weapons (NPT). (1968). http://www.un.org/en/conf/ npt/2005/npttreaty.html. Accessed January 6, 2014.

Treaty on the Nonproliferation of Nuclear Weapons (NPT). (2010). 2010 review conference of the parties to the treaty on the non-proliferation of nuclear weapons. Final document, Vol. I. http:// www.un.org/ga/search/view_doc.asp?symbol=NPT/CONF.2010/50\%20(VOL.I). Accessed January 6, 2014.

United States Department of Defense. (2010, April). Nuclear posture review report. Washington, DC: U.S. Department of Defense.

United States Department of Defense. (2014). Dictionary of military terms. http://www.dtic.mil/ doctrine/dod_dictionary/. Accessed January 6, 2014.

Walker, W. (2000). Nuclear order and disorder. International Affairs, 76(4), 703-724. http://www. jstor.org/stable/2626455.

Wohlstetter, A., Jones, G., \& Wohlstetter, R. (1979). Why the rules have needed changing, Part I. Towards a New Consensus on Nuclear Technology, 1, 36-37.

Zarate, R. (2007). The NPT, IAEA safeguards and peaceful nuclear energy: An "inalienable right," but precisely to what? Unpublished manuscript. http://www.npolicy.org/article_file/ The_NPT_IAEA_Safeguards_and_Peaceful_Nuclear_Energy.pdf. Accessed January 6, 2014. 